\title{
Mevsimlik Tarım İşçileri ve Ailelerinin Să̆lık Kuruluşlarına Başvuru Tercihleri Application Preferences of Seasonal Farm Workers and Their Families for Health Care Institutions
}

\author{
Burcu Iş1ktekin Atalay, Muhammed Fatih Önsüz, Burhanettin Işıklı, Gülsüm \\ Öztürk Emiral, Emine Ayhan, Selma Metintaş
}

Eskişehir Osmangazi Üniversitesi Tıp Fakültesi Halk Sağlığı Anabilim Dalı, Eskisehir, Türkiye

\begin{abstract}
Özet: Çalışmada Eskişehir'deki mevsimlik tarım işçileri ve ailelerinin sağlık kuruluşlarına başvuru tercihlerinin ve etkileyen faktörlerin belirlenmesi amaçlandı. Çalışma, 2014 yaz mevsimi süresince Eskişehir Osmangazi Üniversitesi Eğitim Araştırma Bölgesinde bulunan çadır bölgelerinde çalışmanın olduğu günlerde bulunan ve araştırmaya katılmayı kabul eden 1041 mevsimlik tarım işçisi üzerinde yapılan kesitsel bir araştırmadır. Çalışmada mevsimlik tarım işçilerinin çadır bölgesi, yaşı, cinsiyeti ve içinde bulundukları sezon içerisinde başvuru yaptıkları sağlık kuruluşları ve başvuru sayıları, başvuru nedenleri, başvuru sonucu aldıkları tanı ve müdahaleleri sorgulayan sorulardan oluşan bir anket kullanıldı. Birinci basamak sağlık kuruluşuna başvuru sıklığı ikinci basamak sağlık kuruluşuna başvurudan daha düşük idi. Çoklu lojistik regresyon analizi sonuçlarına göre birinci basamak sağlik kuruluşlarına başvuruda yaş grupları ve çadır bölgesinin merkeze uzaklığı etkili bağımsız değişkenler olarak bulundu. İkinci basamak sağlık kuruluşlarına başvurmada 0-5 yaş grubuna göre 6-14 yaş grubunda başvuru sıklığ azalmaktaydı. Kadınlarda ikinci basamak sağlık kuruluşuna başvurma sıklığı erkeklere göre daha fazla idi. Merkeze yakın çadır bölgesinde oturanlar ikinci basamak sağlık hizmetlerini tercih etmekteydiler. Mevsimlik tarım işçilerinden \%46.6'sının acil durumlarda (kaza, yaralanma), \%38.5'inin hasta olduğunda, \%12.6'sının aşı yapılacağı zaman birinci basamak sağlık kuruluşlarına başvurduğu bulundu. Mevsimlik tarım işçilerinin çalışmak üzere gittikleri ve yılın büyük bir kısmını geçirdikleri bölgelerde karşılaştıkları pek çok sorundan biri de sağlı konusundaki sorunlarıdır. Sağlık ile ilgili sorunlarının çözümünde en önemli müdahale mevsimlik tarım işçisi koruyucu sağlık hizmetlerinin ön planda olduğu birinci basamak sağlık hizmetlerine yönlendirilmesi olacaktır.
\end{abstract}

Anahtar Kelimeler: mevsimlik tarım işçisi, sağlık hizmetleri, başvuru nedenleri, sağlık kurumu

Ișıktekin Atalay B. Önsüz Muhammed F. Işıklı B. Öztürk Emiral G. Ayhan E. Metintaş S. 2017, Mevsimlik Tarım İşçileri ve Ailelerinin Sağlık Kuruluşlarına Başvuru Tercihleri, Osmangazi Tıp Dergisi 2017, 39(3) 18-26～Doi: 10.20515/otd.304501

\begin{abstract}
The aim of the study was to determine the preferences of seasonal farm workers and families for application to health care institutions and the affecting factors. This cross sectional study was performed on 1041 seasonal farmworkers who were accepted to participate in the study, and who were living in tent regions took place in Education and Research area of Eskisehir Osmangazi University during 2014 summer period. An inquiry was used to collect information about seasonal agricultural workers' tent regions, age, and sex, health care institutions they applied during the season and the number of applications, the reasons for application, the diagnosis and the treatment. The frequency of application to the primary health care institutions was lower than the applications to secondary health care institutions. According to the results of multiple logistic regression analysis, age groups and the distance of the tent region to health care institutions were found as effective independent variables in applying to primary health care institutions. The frequency of application to the secondary health care institutions in 6-14 age group was lower than the age group of 0-5. Applications of women to secondary health care institutions were higher than men. Workers who are living in tent areas closer to centrum, preferred secondary health care facilities. Of the application to primary health institutions, $46.6 \%$ were in case of emergency situations (accident, injury), 38.5\% were for illness, and $12.6 \%$ were for vaccination. Health issues are one of the many problems of the seasonal farm workers who go far away from home to work and spend most of the year in that region. The most important intervention in solving health-related problems of seasonal farm workers will be to canalize them to primary health care services where they can access to preventive health care services
\end{abstract}

Key Words: Seasonal farmworkers, health care, reasons for application, health institution

Isiktekin Atalay B. Onsuz Muhammed F. Isikli B. Ozturk Emiral G. Ayhan E. Metintas S. 2017, Application Preferences of Seasonal Farm Workers And Their Families for Health Care Institutions, Osmangazi Journal of Medicine 2017, 39(3) 18-26 Doi: $10.20515 /$ otd.304501 



\section{Giris}

Tarım sektörü, diğer sektörlere kıyasla karşılaşılan sıkıntılar bakımından çalışması zor bir alandır ve dünya çapında tahmini 1,3 milyar işçi istihdam etmektedir ${ }^{(1,2)}$. Mevsimlik Tarım İşçileri (MTI) bazı bölgelerde yoğunlaşmış olsa da tüm ülkelerde ikamet etmektedirler ${ }^{(3)}$. Örneğin Amerika Birleşik Devletleri'nde tahmini 3 milyon göçmen ve MTİ bulunduğu bildirilmektedir ${ }^{(4)}$.

Türkiye'nin tarımda mevsimlik çalışma dönemi, sanayinin hızla gelişmeye başladığ 1 ve tarımda makineleşmenin ortaya çıktığ 1950'li yıllara dayanmaktadır (5). Hizlı nüfus artışıla beraber tarım alanlarının yetersiz kalması, iş imkânlarının kısıtlı olması ve gelişen ulaşım ağının da kolaylaşmasıyla insanlar aileleri ile birlikte sürekli ya da mevsimlik olarak göç etmeye başlamışlardır ve bu durum zamanla yaygınlaşmıştır ${ }^{(5,6)}$. Doğu, Güneydoğu ve Orta Anadolu Bölgelerinde yaşayan bu insanların çoğunlukla aileleri ile birlikte, tarımsal iş gücü talebinin yoğun olduğu Çukurova, Karadeniz, Ege, Marmara ve İç Anadolu Bölgelerine; ekim, dikim, çapa, sulama ve hasat dönemlerinde çalışmak için yılda ortalama 4 aylığına göç ettikleri görülmektedir ${ }^{(5,7)}$.

Türkiye İstatistik Kurumu, Nisan 2015 verilerine göre istihdam edilen işgücünün yaklaşık \%20.7'sini tarım sektörü oluşturmaktadır ${ }^{\left({ }^{(8)}\right.}$. Bu sektörde çalışan MTI'lerin sayısı konusunda kesin bir veri bulunmamaktadır (7). Ancak Çalışma ve Sosyal Güvenlik Bakanlığı verilerine göre sayılarının 300,000 civarında olduğu, fiilen kayıt dışı çalışanlar ve çocuklar ile birlikte en az bir milyonluk bir nüfusu kapsadığ tahmin edilmektedir ${ }^{(6)}$.

MTI'ler göç ettikleri bölgelere eşleri ve çocukları ile birlikte geldiklerinden sağlık sorunları beklenenden fazladır. MTİ ve aileleri yaptıkları işin niteliği, ekonomik yetersizlikleri, göçebe yaşam tarzları, kentsel alanların dışında tarlalarda yaşamaları, yer değiştirme zorunlukları, dil farklılığına bağlı iletişim sorunları, kayıt altında olmamaları, coğrafi ve sosyal izolasyon yaşamaları ve ulaşım zorluklarına bağlı olarak birçok sağlık sorunu ile karşı karşıya kalmaktadırlar ${ }^{(3,6,7)}$. MTİler sağlıklı yaşamdan uzak kalmakla birlikte, sağlık hizmetlerine ulaşmakta da sorun yaşamaktadırlar ${ }^{(3,6)}$. Bu nedenle MTÍ' nin tüm aile bireyleri, özellikle de kadın ve çocuklar risk altındadır ${ }^{(9)}$.

Çalışma, Eskişehir'deki mevsimlik tarım işçileri ve ailelerinin sağlı kuruluşlarına başvuru tercihleri ve etkileyen faktörleri belirlemeyi amaçlamaktadır.

\section{Gereç ve Yöntem}

Çalışma, 2014 yaz mevsimi süresince Eskişehir Osmangazi Üniversitesi Eğitim Araştırma Bölgesinde bulunan MTÍ üzerinde yapılan kesitsel bir araştırmadır.

Mevsimlik tarım işçilerinin gerçek sayısını gösteren bir sağlık kaydı bulunmadığından, çalışma grubu Eğitim-Araştırma Bölgesi'nde bulunan geçici yerleşkelerden oluşan 20 ve üzeri çadıra sahip çadır bölgelerinden alındı. Çalışma için ilgili kurum ve kuruluşlara başvuruldu ve gerekli izinler alındı. Çadır bölgelerinde her çadır bir hane olarak kabul edildi ve hepsi tek tek dolaşıldı. Her hanede, kişiler çalışmanın konusu ve amaci hakkında bilgilendirildikten sonra sözlü onamları alındı. Çalışmanın yapıldığı gün ve saatlerde çadırlarda bulunan bireyler çalışmaya dahil edildi. Anket formlar yüz yüze görüşme yöntemiyle dolduruldu. Mevsimsel tarım işçileri arasında iletişim zorluğu olan kişilere, kendi seçtikleri bireyler aracılığıyla anketler uyguland. Çadır bölgelerinde çalışmanın olduğu günlerde bulunan ve araştırmaya katılmayı kabul eden 1041 kişiye ulaşıldı.

Çalışmanın amacına uygun olarak literatürden faydalanılarak anket form hazırland ${ }^{(7,9,10)}$. Anket form mevsimlik tarım işçilerinin çadır bölgesi, yaşı, cinsiyeti ve içinde bulundukları sezon içerisinde başvuru yaptıkları sağlık kuruluşları (aile hekimi, ilçe entegre hastanesi, devlet hastanesi, üniversite hastanesi ve özel hastane) ve başvuru sayıları, başvuru nedenleri, başvuru sonucu aldıkları tanı ve müdahaleleri sorgulayan sorulardan oluşmakta idi.

Tanıların ICD kodları bulundu ve kaydedildi. Bu tanılar "Türkiye Hastalık Yükü" çalışmasına uygun olarak sistemlere göre sinıflandırıldı (solunum, sindirim, 
obstetrik, jinekolojik, pediatrik, kas-iskelet sistemi, dermatolojik, üriner sistem hastalıkları ve diğer). Aile hekimliği ve ilçe entegre hastaneleri birinci basamak, devlet hastaneleri ikinci basamak sağlık kuruluşu olarak gruplandırıldı. Merkez ilçeye bağlı olan çadır bölgeleri yakın (Sevinç, Sakintepe), ilçelere bağlı olan çadır bölgeleri uzak çadır bölgeleri (Alpu, Bozan, Karahöyük, Osmaniye) olarak siniflandirildi.

Elde edilen veriler, bilgisayar ortamında IBM SSPS (versiyon 20.0) Programında değerlendirildi. Analizler için Ki-kare
Analizi kullanıldı. Sağlı kuruluşlarına başvuru üzerine etkili bağımsız değişkenleri belirlemek için çoklu lojistik regresyon analizi yapıldı. İstatistiki anlamlılık sınırı olarak $\mathrm{p}<0.05$ kabul edildi.

\section{Bulgular ve Analizler}

Çalışma grubunu oluşturan 1041 kişinin yaş ortalamas1 $20.0 \pm 15.9$ (min.:0, max.:87) idi. Katılımciların 537'si (\%51.6) kadın, 532'si (\%51.1) ise merkez ilçeye bağlı yakın çadır bölgelerinde yaşamaktaydı. Çalışma grubunun bazı sosyodemografik özelliklerine göre dağılımı Tablo 1'de verildi.

Tablo 1.

Çalışma grubunun bazı sosyodemografik özelliklere göre dă̆ılımı

\begin{tabular}{|c|c|c|}
\hline Değişkenler & $\mathbf{n}$ & $(\%)$ \\
\hline \multicolumn{3}{|l|}{ Yaş } \\
\hline $0-5$ & 198 & 19.0 \\
\hline $6-14$ & 271 & 26.0 \\
\hline $15-49$ & 487 & 46.8 \\
\hline 50 yaş ve üstü & 85 & 8.2 \\
\hline \multicolumn{3}{|l|}{ Cinsiyet } \\
\hline Erkek & 504 & 48.4 \\
\hline Kadin & 537 & 51.6 \\
\hline \multicolumn{3}{|l|}{ Çadır bölgesi } \\
\hline Yakın & 532 & 51.1 \\
\hline Uzak & 509 & 48.9 \\
\hline
\end{tabular}

Birinci basamak sağlık kuruluşlarına başvuran 193 kişi (\%18.6), ikinci basamak sağlık kuruluşlarına başvuran 315 kişi (\%30.2), hiçbir sağlık kuruluşuna başvurmayan ise 533 kişi (\%51.2) vardı. Sağlık kuruluşlarına başvuranlarda, başvuru sayısı ortanca değeri 1 (min.:1, max.:22) idi. Birinci basamak sağlık kuruluşuna başvuru sıklığı (\%18.6), ikinci basamak sağlık kuruluşuna başvurudan (\%30.2) daha düşüktür $\left(X^{2}: 38.75 ; p<0.001\right)$.

Birinci basamak sağlık kuruluşuna en yüksek başvuru \%27.3 ile 0-5 yaş grubunda iken, en düşük başvuru orantısı 15-49 yaş grubunda (\%15.2) idi $\left(\mathrm{X}^{2}: 16.70 ; \mathrm{p}: 0.001\right)$. İkinci basamak sağlık kuruluşuna başvurmada en yüksek \%36.1 ile 15-49 yaş grubunda iken, en düşük başvuru oranı 6-14 yaş grubunda $(\% 18.5)$ görüldü $\left(X^{2}: 26.08 ; p<0.001\right)$. Birinci basamağa başvuru yüzdesi cinsiyete göre değişiklik göstermemekteydi $\left(\mathrm{X}^{2}: 0.053\right.$; p:0.818). Oysa ikinci basamak sağlik kuruluşuna başvurma oranı kadınlarda (\%36.1) erkeklere (\%24) göre daha fazlayd 1 $\left(x^{2}: 12.043 ;\right.$ p:0.001). Merkeze uzak çadır bölgelerinin birinci basamak sağlık 
kuruluşlarına (\%34.8) başvurma yüzdesi daha yüksek iken $\left(\mathrm{X}^{2}: 173.80 ; \mathrm{p}<0.001\right)$, ikinci basamak sağlik kuruluşlarına başvurmada merkeze yakın çadır bölgelerinin (\%35.7) başvurusu daha yüksek idi $\left(\mathrm{X}^{2}: 15.34 ; \mathrm{p}<0.001\right)$.

Çoklu lojistik regresyon analizi sonuçlarına göre birinci basamak sağlık kuruluşlarına başvuruda yaş grupları ve çadır bölgesinin merkeze uzaklığı etkili bağımsız değişkenler olarak bulundu. Yaş artıkça birinci basamak sağlık kuruluşlarına başvurma sıklı̆̆ 1 azalırken, çadır bölgesi merkeze uzak olanlarda sıklık artmaktaydı. İkinci basamak sağlık kuruluşlarına başvurmada 0-5 yaş grubuna göre 6-14 yaş grubunda başvuru sıklı̆̆1 azalmaktaydı. Kadınlarda ikinci basamak sağlık kuruluşuna başvurma sıklığı erkeklere göre daha fazla idi. Çadır bölgesi merkeze uzak olanların ikinci basamak sağlık kuruluşlarına başvuruları, çadır bölgesi merkeze yakın olanlara göre daha düşüktü. Çalışma grubunun sağlı kuruluşu başvurularının bazı sosyodemografik özelliklerinin çok değişkenli analize göre dağılımı Tablo 2'de verildi.

Tablo 2.

Çalışma grubunun sağlık kuruluşu başvurularının bazı sosyodemografik özelliklerinin çok değişkenli analiz sonuçlarına göre dă̆ılımı

\begin{tabular}{|c|c|c|c|c|}
\hline \multirow[t]{2}{*}{$\begin{array}{c}\text { Sosyodemografik } \\
\text { ozellik }\end{array}$} & \multicolumn{2}{|c|}{$\begin{array}{c}\text { 1.Basamak sağlık kuruluşlarına } \\
\text { başvurma }\end{array}$} & \multicolumn{2}{|c|}{$\begin{array}{c}\text { 2.Basamak sağlık kuruluşlarına } \\
\text { başvurma }\end{array}$} \\
\hline & $n(\%)$ & $\begin{array}{l}\text { Çok değişkenli } \\
\text { analiz } \\
\text { OR (\%95 GA*) }\end{array}$ & $n(\%)$ & $\begin{array}{l}\text { Çok değişkenli } \\
\text { analiz } \\
\text { OR (\%95 GA*) }\end{array}$ \\
\hline \multicolumn{5}{|l|}{ Yaş grupları } \\
\hline $0-5$ & $54(27.3)$ & 1 & $62(31.3)$ & 1 \\
\hline $6-14$ & $44(16.2)$ & $055(0.33-0.92)$ & $50(18.5)$ & $0.45(0.20 .70)$ \\
\hline $15-49$ & $74(15.2)$ & $0.46(0.29-0.73)$ & $176(36.1)$ & $1.10(0.76-1.58)$ \\
\hline 50 yaş ve üstü & $21(24.7)$ & $0.85(0.44-1.65)$ & $27(31.8)$ & $0.95(0.55-1.67)$ \\
\hline \multicolumn{5}{|l|}{ Cinsiyet } \\
\hline Erkek & $92(18.3)$ & & $121(24.0)$ & 1 \\
\hline Kadın & 101(18.8) & & $194(36.1)$ & $1.72(1.30-2.27)$ \\
\hline \multicolumn{5}{|l|}{ Çadır bölgesi } \\
\hline Yakın & $16(3.0)$ & 1 & $190(35.7)$ & 1 \\
\hline Uzak & $177(34.8)$ & $17.18(10.09-29.25)$ & $125(24.6)$ & $0.56(0.42-0.74)$ \\
\hline
\end{tabular}

\section{$G A^{*}$ Güven aralığ}

Mevsimlik tarım işçilerinden \%46.6'sının acil durumlarda (kaza, yaralanma), \%38.5'inin hasta olduğunda, \%12.6'sının aş1 yapılacağ1 zaman birinci basamak sağlık kuruluşlarına geldiği bulundu. Katılımcıların başvurduklarında ise yapılan işlemlerin \%66.8'i reçete yazılması, \%16.0'1 enjeksiyon yapılması, \%11.8'i müşaadeye alınması şeklinde olduğu saptandı. Mevsimlik tarım işçilerinin birinci basamak sağlık hizmetlerine bașvurduklarında aldıkları tanıların \%22.9'u sindirim sistemi hastalıkları, \%19.8'i solunum sistemi hastal1klar1, \%15.6's1 pediatrik hastalıklar, \%14.1'i kas-iskelet sistemi hastalıkları ile ilgili olduğu bulundu. Mevsimlik tarım işçilerinin birinci basamak sağlık kuruluşunda aldıkları tanılara göre dağılımı Grafik 1'de verildi. 


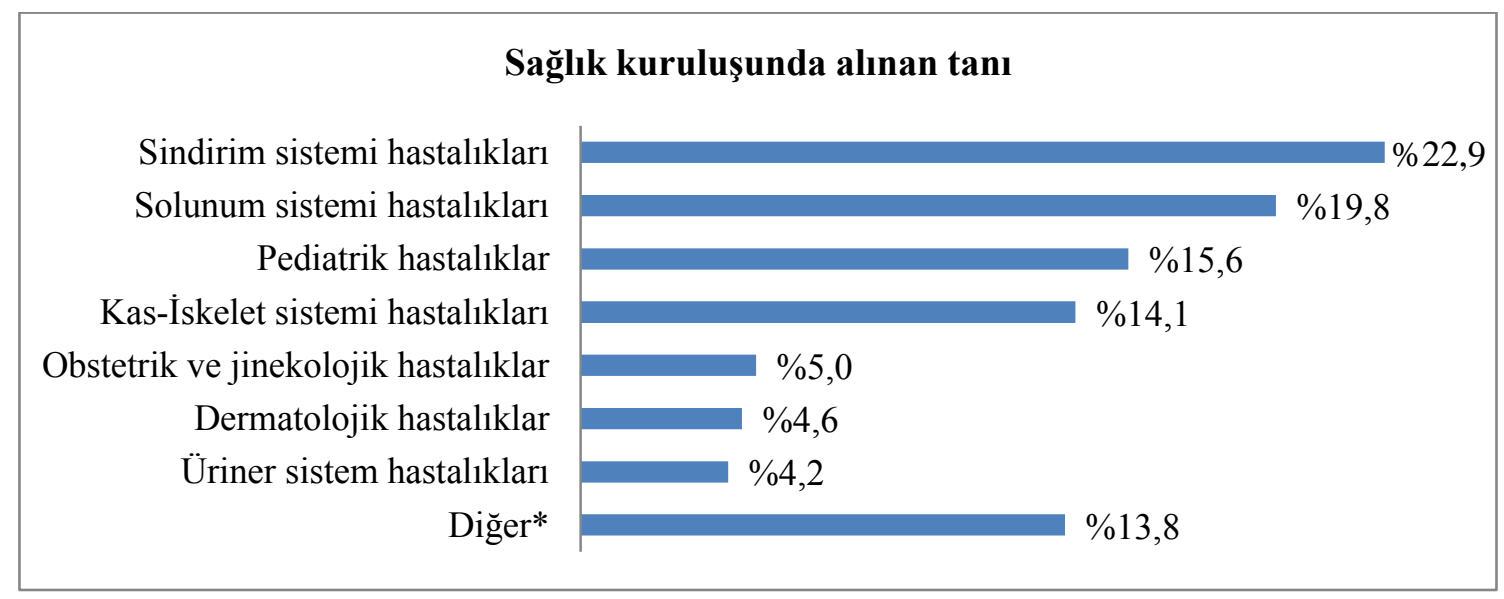

Grafik 1.Mevsimlik tarım işçilerinin birinci basamak sağllk kuruluşunda aldıkları tanılara göre dă̆ılımı

* Santral sinir sistemi hastalıkları, kardiyolojik hastalıklar, kulan burun boğaz hastalıkları, göz hastalıkları, kan hastalıkları, psikiyatrik hastalıklar, ağız-diş problemleri, travmatik hastalıklar, endokrin hastalıkları

\section{Tartışma}

Çalışma MTİ'nin tarım sezonunda göçle geldikleri bir bölgede sağlık kuruluşlarına başvurularını irdelemek amacıyla yapıldı. Ülkemizde MTİ ile ilgili olarak yapılan çalışmalar çoğunlukla bu grubun yoğun olarak yaşadığı Türkiye'nin Güneydoğu Anadolu Bölgesi'nde gerçekleştirilmiştir. Çalışma ise MTİ'nin evlerinden ayrılarak çalışmak için geldikleri ve yaklaşık yılın yarısında çoğunu geçirdikleri Eskişehir kırsalındaki çadır bölgelerinde gerçekleştirilmiştir. Çalışmaya katılanların yarısının herhangi bir sağlik kuruluşuna başvurmadığ 1 ve bir sağlık kurulușuna başvuranların ise daha çok ikinci basamak sağlık kuruluşlarına başvurdukları belirlendi. Mevsimlik tarım iş̧̧ilerinin yoğun olarak yaşadığı Türkiye'nin Güneydoğu Anadolu Bölgesi'nde yapılan bir çalışmada aile üyelerinin üçte birinin hastalandıklarında bir sağlık kuruluşuna başvurmadıkları bildirilmiştir. Aynı çalışmada, her dört kişiden birinin birinci basamak sağlık hizmetini alabilmesi için kayıtlı olması gereken aile hekimini bildiği, bir aile hekimi olduğunu belirtenlerin ise sadece dörtte birinin aile hekimine başvurduğu belirtilmiştir ${ }^{(11)}$. Aynı bölgeden yapılan bir bașka çalıșmada ise MTİ'lerinin beşte birinin tarlada çalışırken, onda birinin ise evde hastalandıklarında sağlık kuruluşuna başvurmadıkları rapor edilmiştir. Aynı çalışmada ayrıca başvuranların da yaklaşık dörtte üçünün ikinci basamak sağlık kuruluşlarına, buna karşın sadece onda birinin birinci basamak sağlik kuruluşlarına başvurduğu belirtilmiştir ${ }^{(12)}$. Yapılan birçok çalışmada da benzer şekilde tarım işçileri ve ailelerinin sağlık hizmetlerinden yeterince yararlanamadıkları belirtilmektedir (13-18). Araştırmamızda sağlı kuruluşuna başvurmama oranları literatüre göre yüksektir. $\mathrm{Bu}$ durum ülkemizde yapılan çalışmaların çoğunlukla MİT'nin yaşadıkları Güneydoğu Anadolu Bölgesi'nde yapılmış olmasının bir sonucu olabilir. MTİ yaşadıkları bölgelerde sağlık hizmetlerinden yararlanabilme olanakları çalışmak için gittikleri bölgelere göre daha yüksektir. Oysa MTI'nin çalıştıkları bölgelerde sağlı hizmetlerine ulaşabilmelerinin sağlanması çok daha önemlidir. Çünkü MTİ ve ailelerinin çalışmak için gittikleri yerlerde kentsel alan dışında çadırlarda yaşamaları, s1k sık yer değiştirmeleri, dil sorunları, sağlığa erişim ve sağlıklarını koruma konusunda bilgi yetersizlikleri nedeniyle kapsamlı ve ulaşılabilir sağlık hizmetine ihtiyaçları daha fazladır. MTİ'nin yarısının herhangi bir sağlık kuruluşuna başvurmadığı ve başvuranlarında daha çok ikinci basamak sağlık kuruluşlarını tercih ettikleri görüldü. Oysa çalışmak için gittikleri yerlerde yılın yarısından daha fazla kalan bu grup için gezici sağlık hizmeti ile özellikle koruyucu sağlık hizmetlerinin götürülmesi sağlık hizmetlerine ulaşımı arttırmak için önemli bir müdahale olabilir. Çalışılan bölgedeki MTİ'nin sağlık gereksinimleri ilk gittikleri anda tespit edildikten sonra bu sorunların çözümü için gerekli araçlarla donatılmış araçlarla gezici sağlık hizmetleri verilmelidir. Yapılan 
çalışmalarda MTİ'ne yönelik olarak verilen gezici sağlı hizmetlerinde özellikle anaçocuk sağlığ 1 hizmetlerine erişimin anlamlı olarak arttığ bulundu ${ }^{(15,19)}$.

Birinci basamak sağlık kuruluşlarına başvuruyu yaş ve çadır bölgesinin sağlık kuruluşuna uzaklığı etkilerken, ikinci basamak sağl1k kuruluşuna başvuruyu yaş, cinsiyet ve çadır bölgesinin sağlık kuruluşuna uzaklığ1 etkilemekte idi. Yapılan çoklu lojistik regresyon analizi sonuçlarına göre yaş, cinsiyet ve çadır bölgesinin sağlık kuruluşuna mesafesi sağllk kuruluşlarına başvuruyu etkileyen faktörler olarak bulundu. Literatürde yaş ve cinsiyet sağlık hizmeti kullanımını etkileyen bireysel faktörler arasında gösterilmektedir (20). Yaşın sağlık hizmeti kullanımını etkilediği yönünde bir sonuç MTI'nde yapılan zaten az sayıda olan çalışmaların hiçbirisinde belirtilmemiştir $(21,22)$. Ancak literatürde yaşın sağlık hizmeti kullanımını etkilediğini bildiren çalışmalar da bulunmaktadır ${ }^{(23,24)}$. Yaş açısından değerlendirildiğinde, özellikle çocukların ve yaşlıların daha çok sağllk hizmeti kullandıkları bildirilmekte olup neden olarak da bu yaş gruplarında sağlık hizmetine olan ihtiyacın daha çok olması belirtilmektedir ${ }^{(25)}$. Araștırma sonucunda özellikle birinci basamak sağlık kuruluşlarına başvurunun 0-5 yaş grubu çocuklarda daha çok olduğu bulundu. Japonya'da yapılan bir çalışmada 18 yaş altındaki çocukların yetişkinlere göre sağlık hizmetlerini daha çok kullandığ 1 bildirilmiştir ${ }^{(26)}$. Ülkemizde birinci basamak sağlık kuruluşlarında eskiden beri etkin şekilde bağışıklama hizmetleri ve ana-çocuk sağlı̆̆ hizmetleri gibi koruyucu sağlı hizmetlerinin veriliyor olması bu sonucu ortaya çıkarmış olabilir.

Araştırma sonucunda ikinci basamak sağlık kuruluşlarına başvuruların kadınlarda daha yüksek olduğu bulundu. Literatürde hem genel toplumda hem de MTİ ile yapılan çalışmalarda kadınların sağlık hizmetlerini daha çok kullandıkları bildirilmiştir ${ }^{(14,21,22,27-}$ $\left.{ }^{29}\right)$. Kadınların gebelik, doğum, aile planlaması gibi üreme biyolojileri ile ilgili konularda sağlık hizmetlerini kullanmaları, sağlık algıları, hastalık oranlarının yüksekliği ve özellikle koruyucu sağllk hizmetlerini daha fazla kullanmaları gibi nedenlerin bu sonucun ortaya çıkmasında etkili olduğu belirtilmektedir ${ }^{(28)}$. Literatürle benzer şekilde ülkemizde MTİ'de yapılan çalışmalarda da daha yüksek oranlarda kadınların sağlıklarını kötü olarak algıladıkları belirtilmektedir ${ }^{(11,12)}$. Yine MTİ açısından kadınların genellikle çadırda kalmaları ve yerel halka göre daha çok çocuk sahibi olmaları bu sonucu ortaya çıkarmış olabilir.

Araştırmada çadır bölgesinin mesafesi de sağlık hizmeti kullanımını etkileyen bir faktör olarak bulundu. Uzak çadır bölgelerinde kalanların özellikle birinci basamak sağlık hizmetlerini daha çok kullandığı belirlendi. Literatürde sağlık hizmeti kullanımının mesafeden etkilendiğini belirten çalışmalar bulunmaktadır ${ }^{(30-33)}$. Sağlık hizmeti sunan kurumların kişilere fiziken ve zaman olarak yakın olmasının kullanımı arttırma yönünde bir etkisi olacağı söylenebilir. Araştırma sonucumuzun önemli olan boyutu ise birinci basamak sağlık hizmetlerinin uzak çadır bölgelerinde kalanlar tarafından daha çok kullanılmasıdır. Ülkemizde birinci basamak sağlık hizmetlerinin kapsamı ve MTI'lerinin ihtiyaçlarını karşılayabilme kapasitesi bu sonucu ortaya çıkarmış olabilir. Araştırmaya katılan MTİ'nin birinci basamak sağlık kuruluşlarına daha çok kaza, yaralanma gibi acil durumlarda ve aşılama hizmetleri için başvurduklarını ve daha çok reçete yazdırdıkları belirtmeleri de bu düşünceyi destekler niteliktedir. $\mathrm{Bu}$ sonuçlar gözönüne alındığında MTİ'lerinin sağlık konusunda temel ihtiyaçlarını çoğunlukla birinci basamak sağlık kuruluşlarında karşıladıkları görülmektedir. $\mathrm{Bu}$ sonuç MTI'lerinin çalışmak için gittikleri bölgelerde birinci basamak sağlık hizmetlerinin buna göre bazı değişikliklerle organize edilmesinin önemli olacağını göstermektedir. $\mathrm{Bu}$ bölgelerde MTI'lerinin sağlık sorunları çeşitli yönleri ile değerlendirilmeli ve ana çocuk sağlığından iş sağllğına kadar geniş bir perspektifte bu hizmetler organize edilmelidir. Ayrica bu bölgelerde çalışan sağlık personelleri de MTİ'lerinin sağlık hizmeti ihtiyaçlarına göre bu geniş perspektifte ele alınması gereken konularda daha bilinçli ve duyarlı hale getirilmelidir. $\mathrm{Bu}$ şekilde MTÍnnin sağlık düzeyleri arttırılarak daha sağlıklı bir şekilde yaşayıp çalışmaları sağlanabilir.

Birinci basamak sağlık kuruluşlarına başvuran MTI'lerinde en çok görülen sağlık sorunları sindirim sistemi hastalıkları, solunum sistemi hastalıkları, pediatrik hastalıklar ve kas-iskelet sistemi hastalıkları idi. MTİ'nin yoğun olarak yaşadığı Türkiye'nin Güneydoğu Anadolu Bölgesi'nde yapılan çalışmalarda en sık görülen hastalıklar üst solunum yolu 
hastalıkları ve kas-iskelet sistemi hastalıkları olarak bildirilmiştir ${ }^{(11,12)}$. Literatürde MTI'de en sık görülen sağlik problemleri arasında mesleki kaza ve yaralanmalar ve kas-iskelet sistemi hastalıkları, solunum sistemi hastalıkları ve enfeksiyon hastalıkları olarak belirtilmektedir (15,34-36). Araştırmanın sonuçları literatürle benzerlik göstermektedir. MTI'nin çok zor ve sağlıksız koşullarında yaşadıkları bilinmektedir ${ }^{(11,12)}$. Bu durum sağlı̆̆ın en önemli belirleyicilerinden biri olan sosyoekonomik düzeyi düşük olan MTİ'ni sağlık açısından riskli bir grup haline getirmektedir. Ayrıca literatürde MTİ'lerinin yeterli ve sağlıklı gıdaya ulaşma konularında sorunları olduğu da bildirilmektedir ${ }^{(11,12)}$. Bu nedenlerle sindirim sistemi ile ilgili sağlık sorunlarını yoğun olarak yaşamaları beklenen bir sonuçtur. Yine hem çalışma ortamları hem de yaşadıkları ortamlar düşünüldüğünde pestisit etkilenmeleri başta olmak üzere solunum sistemini olumsuz etkileyebilecek birçok ajanla karşılaşmaktadırlar ${ }^{(37)}$. Sağlık risklerine karşı korunma konusunda MTİnin bilgi eksikliği de belirtilmektedir ${ }^{(11,12)}$. Hem pestisit etkilenimleri hem de sağlık risklerine karşı korunma konusundaki bilgi eksiklikleri nedeniyle solunum sistemi hastalıklarını sik görülmesi de beklenen bir sonuç olarak değerlendirilebilir. MTİ'nin sağlıksız koşullarda, herhangi bir önlem alınmadan çalışmaları kas-iskelet sistemi hastalıkları başta olmak üzere mesleksel kaza ve yaralanmaları önemli bir sağlık sorunu haline getirmektedir ${ }^{(15)}$. MTİ çalıştıkları bölgelere çocukları ile birlikte gitmektedirler. Çocuk sağlı̆̆ının ekonomik, çevresel ve sosyokültürel faktörlerden etkilendiği de düşünüldügünde karşılaşılan tüm olumsuzluklardan çocukların da etkilenmesi doğal bir sonuçtur. Ülkemizde MTI'nin çocuklarında yapılan araştırmalarda beslenme bozuklukları, paraziter hastalıklar, anemi, bağışıklama sorunları ve gelişme gerilikleri önemli sorunlar olarak ön plana çıkmaktadır $(18,19,38)$

\section{Sonuç}

MTI'nin çalışmak üzere gittikleri ve y1lın büyük bir kısmını geçirdikleri bölgelerde karşılaştıkları pek çok sorundan biri de sağl1k konusundaki sorunlarıdır. Sağlık ile ilgili sorunlarının çözümünde en önemli müdahale MTİ'nin koruyucu sağlık hizmetlerinin ön planda olduğu birinci basamak sağlık hizmetlerine yönlendirilmesi olacaktır. $\mathrm{Bu}$ konuda öncelikle mevsimlik tarım işçileri ve aileleri ile ilgili çalışmak üzere gittikleri bölgelerde güvenilir bir sağlık veri tabanı oluşturulmalı ve bu veri tabanı bu bölgelerde birinci basamak sağlik hizmetlerinin yürütülmesinden sorumlu olan TSM'lerin kontrolünde aile hekimlerinde bulunmalıdır. MTİ'nin temel sağlık hizmetlerini TSM ve aile hekimlerinin koordinasyonunda almaları sağlanmalıdır. MTI'nin sağlık sorunlarının çözümünde gezici sağlık hizmeti verilmesinin pozitif etkileri olduğu literatürde belirtilmektedir ${ }^{(19)}$. Ancak MTI'lerinin sağlık sorunlarının çok boyutlu olduğu düşünüldügünde birinci basamak sağlık hizmetlerinin MTİ'nin sağlık sorunlarının çözümü yönünde güçlendirilmesinin ve düzenlenmesinin çok daha yararlı olacağı düşünülmektedir. Bu şekilde MTI'ne yönelik bireysel ve çevresel sağlik hizmetlerinin yanı sıra sürveyans, iş sağlığ 1 gibi hizmetler de bir bütünlük içerisinde daha etkin bir şekilde verilebilir. Bu konuda yasal düzenlemelerin yapılarak sektörlerarası işbirliği yapılması da uygun olacaktır. Son olarak ülkemizde MTI ile ilgili yapılan çalışmaların çoğunun MTI'nin sağlık hizmeti kullanımı ile ilgili olduğu görülmektedir. Çalışma, MTİ'nin sağlık hizmeti kullanımında tercih ettikleri sağlık hizmeti türünü göstermesi açısından ilk çalışmalardan biridir. Bu konuda daha çok epidemiyolojik çalışmaların yapılması MTI'nin sağlık sorunlarının çözümü için sağllk hizmetlerinin düzenlenmesinde ve yasal alt yapının oluşturulmasında yardımcı olacaktır. 


\section{KAYNAKLAR}

1. European Comission (2013). Agricultural Economics Briefs: How many people work in agriculture in the European Union? http://ec.europa.eu/agriculture/sites/agricultur e/files/rural-area economics/briefs/pdf/08_en. pdf

2. International Labour Organization (2015). Occupational Safety and Health: Agriculture: a hazardous work http://www.ilo.org/safework/areasofwork/haz ardous-work/WCMS_110188/lang-en/index.htm

3. Rosenbaum S, Shin P. (2005). Migrant and Seasonal Farmworkers: Health Insurance Coverage and Access to Care. Washington: Kaiser commission on medicaid and the uninsured.

4. National Center for Farmworker Health (2012). Farmworker health factsheet: facts about farmworkers. Buda.

5. Öz CS, Bulut E. Mevsimlik tarım işçilerinin Türk hukuk sistemi içerisindeki yeri. ÇSGB Çalışma Dünyası Dergisi, 2013;1(1), 94-111.

6. Mevsimlik İşçi Göçü İletişim Ağı. (2012). Tarımda mevsimlik işçi göçü Türkiye durum özeti. İstanbul.

7. T.C. Çalışma ve Sosyal Güvenlik Bakanlığı (2010). Mevsimlik gezici tarım işçilerinin çalışma ve sosyal hayatlarının iyileştirilmesi stratejisi ve eylem planı. Ankara.

8. Türkiye İstatistik Kurumu (2015). İşgücü İstatistikleri, Nisan 2015 http://www.tuik.gov.tr/PreHaberBultenleri.do ?id=18639,

9. Bakırcı N. Tarımda çalışanların sağlığı ve güvenliği. Mesleki Sağlık ve Güvenlik Dergisi, 2011;39, 7-13.

10. Kaya M, Özgülnar N. Mevsimlik (gezici/geçici) tarım işçilerinin iki yerleşim birimindeki yaşam koşulları ve sağlık durumlarına niteliksel bakıș. Turk Journal Public Health, 2015;13(2), 115-122.

11. Harran Üniversitesi Tarımda İş Sağlığı ve Güvenliği Uygulama ve Araştırma Merkezi. (2014). GAP tarımda çalışanların sağlığ araştırması 2013. Şanlıurfa.

12. Şimşek, Z. (2012). Mevsimlik tarım işçilerinin ve ailelerinin ihtiyaçlarının belirlenmesi araştırması raporu 2011. Ankara: Damla Matbaacilık Ltd. Sti.

13. Villarejo D, McCurdy SA, Bade B, Samuels S, Lighthall D, Williams D. The health of California's immigrant hired farmworkers. Am J Ind Med, 2010; 53, 387-397.

14. Georges A, Alterman T, Gabbard S, et al. Depression, social factors, and farmworker health care utilization. J Rural Health, 2013;29, s7-s16.

15. Arcury TA, Quandt SA. Delivery of health services to migrant and seasonal farmworkers. Annu Rev Public Health, 2007;28, 345-363.

16. Hansen E, Donohoe M. Health issues of migrant and seasonal farmworkers. J Health Care Poor and Underserved, 2003;14,153164.

17. Weathers AC, Garrison HG. Children of migratory agricultural workers: The ecological context of acute care for a mobile population of immigrant children. Clin Pediatr Emerg Med, 2004;5(2), 120-129.

18. Koruk I, Simsek Z, Koruk ST, Doni N, Gürses G. Intestinal parasites, nutritional status and physchomotor development delay in migratory farm worker's children. Child Care Health Dev,2010; 36, 888-894.

19. Simsek Z, Koruk I, Doni NY. An operational study on implementation of mobile primary healthcare services for seasonal migratory farmworkers, Turkey. Matern Child Health J, 2012;16, 1906-1912.

20. Andersen R, Newman JF. Societal and individual determinants of medical care utilization in the United States. Milbank Q, 2005; 83(4), 1-28.

21. McCoy HV, Williams ML, Atkinson JS, Rubens M. Structural characteristics of migrant farmworkers reporting a relationship with a primary care physician. J Immigr Minor Health, 2016;18, 710-714.

22. Hoerster KD, Mayer JA, Gabbard S, et al. Impact of individual-, environmental-, and policy-level factors on health care utilization among US farmworkers. Am J Public Health, 2011;101, 685-692.

23. Woods CR, Arcury TA, Powers JM, Preisser JS, Gesler WM. Determinants of health care use by children in rural western North Carolina: results from the Mountain Accessibility Project. Pediatrics, 2003;112(2), e143-152.

24. Mendoza-Sassi R, Beria JU, Barros AJ. Health services utilization: a systematic review of related factors. Cad Saude Publica, 2001;17(4), 819-832.

25. Rosenberg MW, Hanlon NT. Access and utilization: a continuum of health services environments. Soc Sci Med,1996;43, 975983.

26. Ishida $\mathrm{Y}$, Ohde $\mathrm{S}$, Takahashi $\mathrm{O}$, et al. Factors affecting health care utilization for children in Japan. Pediatrics, 2012;129(1), e113-119.

27. Ladwig KH, Marten-Mittag B, Formanek B, Dammann G. Gender differences of symptom reporting and medical health care utilization in the German population. Eur J Epidemiol, 2000; 16(6), 511-518.

28. Bertakis KD, Azari R, Helms LJ, Callahan EJ, Robins JA. Gender differences in the utilization of health care services, J Fam Pract, 2000; 49(2), 147-152.

29. Redondo-Sendino A, Guallar-Castillon $P$, Banegas JR, Rodriguez-Artalejo F. Gender differences in the utilization of health-care services among the older adult population of Spain. BMC Public Health, 2006;16(6), 155.

30. Field KS, Briggs DJ. Socio-economic and locational determinants of accessibility and utilization of primary health-care. Health Soc Care Community, 2001;9(5), 294-308.

31. Babar TS, Juanita H. Health seeking behaviour and health service utilization in Pakistan: challenging the policy makers. J Public Health, 2005;27(1), 49-54. 
32. Awoyemi T, Obayelu A, Opaluwa I. Effect of distance on utilization of health care services in rural Kogi State, Nigeria. J Hum Ecol, 2011; 35(1), 1-9.

33. Şenol V, Çetinkaya F, Balcı E. Factors associated with health services utilization by the general population in the center of Kayseri, Turkey. Turkiye Klinikleri J Med Sci, 2010;30(2), 721-730.

34. Arcury TA, Estrada JM, Quandt SA. Overcoming language and literacy barriers in safety and health training of agricultural workers. J Agromedicine, 2010;15(3), 236248.

35. Cameron L, Lalich $\mathrm{N}$, Bauer $\mathrm{S}$, et al Occupational health survey of farm workers by camp health aides. J Agric Saf Health, 2006;12, 139-153.

36. Anthony M, Williams JM, Avery AM. Health needs of migrant and seasonal farmworkers. $\mathrm{J}$ Community Health Nurs, 2008;25(3), 153160.

37. Gomez M, Hwang S, Lin S, Stark A, May J, Hallman E. Prevelance and predictors of respiratory symptoms among New York farmers and farm residents. Am $\mathrm{J}$ Ind Med,2004; 46, 42-54.

38. Şimsek Z, Koruk İ. The effects of migratory seasonal farmwork on psychomotor development and growth among children ages 0-5 years in Southeastern Anatolia. Turk J Public Health, 2011;9(3), 157-165. 